\title{
MỘT SỐ ĐẶC ĐIỂM LÂM SÀNG, CẬN LÂM SÀNG \\ DẬY THÌ SỚM VÔ CĂN Ở TRẺ GÁI
}

Nguyê̂n Thị Diễm Chi ${ }^{1}$, Hoàng Thị Thủy Yên ${ }^{2}$

1. Bệnh viện Trung uoong Huế

2. Trường Đại học Y Dược Huế

DOI: $10.47122 / v j d e .2020 .38 .12$

\section{ABSTRACT \\ Clinical and paraclinical characteristics in girls with idiopathic precocious puberty}

Objective: Describe some clinical and paraclinical characteristics aiming to orient early diagnosis of puberty forms in our current medical actuality. Methods: Crosssectional descriptive retrospective study on 83 girls diagnosed of precocious puberty at thePediatric department of Hue University Hospital and at Pediatric Center of Hue Central Hospital from March 2010 to March 2016. Results: There was a clear difference of age at the diagnosis moment, mean age of peripheral precocious puberty group was $3,93 \pm 2,22$ years, younger statistically significantly than that of central precocious puberty group (CPPG). Bone age advanced over chronological age significantly (by more than 1 year) was also a manifestation of central precocious puberty. There was a clear difference of the uterus - ovaries sonographic index between two groups. There was a clear difference of gonadic axis hormon concentration: basic FSH, LH serum levels between two groups. Basic serum LH level increased significantly, $\mathrm{p}<0,0001$ in CPPG. Conclusion: Clinically, age at mammary gland appearance characteristics was an important data valuable to orient early diagnosis of puberty forms; bone age advanced over chronological age significantly (by more than 1 year) was also a manifestation of central precocious puberty. Paraclinically, a pelvic ultrasoundwas a medical test with highly diagnosis valuebut required well - trained and highly skilled technician and how to prepare for the exam. Quantitative method of basic LH serum level by $2^{\text {nd }}$ generation immune assays could be used to evaluate maturation level of gonadotropic axis. It is possible to use low dose aGnRH dynamic test to differentiate central precocious puberty and peripheral precocious puberty.

Keywords: idiopathic precocious puberty

\section{TÓM TẮT}

Mục tiêu: Mô tả đặc điểm lâm sàng và xét nghiệm cận lâm sàng theo phân loại dậy thì sớm vô căn ở trẻ gái. Đối tự̛ng và phương pháp nghiên cúu: Phương pháp mô tả cắt ngang trên 83 trẻ gái được chẩn đoán dậy thì sớm tại Khoa Nhi, Bệnh viện Trường ĐHYD Huế và Trung tâm Nhi, Bệnh viện Trung ương Huế, từ tháng 3 năm 2010 đến tháng 3 năm 2016. Kết quả: Ở thời điểm chẩn đoán tuổi trung bình của nhóm nghiên cứu là 5,11 $\pm 2,63$, Nhóm dậy thì sớm ngoại vi có tuổi trung bình là $3,93 \pm 2,22$, thấp hơn rõ rệt với nhóm dậy thì sớm trung ương. Tuổi xương lớn hơn tuổi thực cũng là biểu hiện của dậy thì sớm trung ương. Có sự khác biệt rõ rệt các chỉ số siêu âm tử cung-buồng trứng theo phân loại dậy thì sớm trung ương và ngoại biên. Có sự khác biệt rõ rệt nồng độ hormon trục sinh dục FSH, LH nền theo phân loại dậy thì. Nồng độ LH nền tăng cao có ý nghĩa, p $<0,0001$ trong dậy thì trung ương. Kết luận: Về lâm sàng, đặc điểm tuổi xuất hiện tuyến vú là dữ kiện quan trọng có giá trị định hướng chẩn đoán sớm các thể dậy thì; tuổi xương lớn hơn tuổi thực một cách có ý nghĩa ( $>1$ năm) cũng là biểu hiện của dậy thì sớm trung ương. Về cận lâm sàng, siêu âm tử cung buồng trứng là một xét nghiệm kỹ thuật có giá trị chẩn đoán cao nhưng đòi hỏi có kỹ thuật viên được huấn luyện tốt, và phải hẹn chuẩn bị tốt cho bệnh nhân. Phương pháp định lượng nồng độ hormon LH nền bằng các phương pháp miễn dịch thế hệ 2 có thể đánh giá mức độ 
trưởng thành của trục hướng sinh dục.

Chịu trách nhiệm chính: Nguyễn Thị Diễm Chi

Ngày nhận bài: 07/01/2020

Ngày phản biện khoa học:14/01/2020

Ngày duyệt bài: 26/02/2020

Email: nguyendiemchi@gmail.com

ĐT: 0912398499

\section{1. ĐĀT VẤN ĐỀ}

Dậy thì sớm (sexual precocity) được định nghĩa khi các dấu hiệu dậy thì đầu tiên xuất hiện trước 8 tuổi ở trẻ gái và trước 9 tuổi ở trẻ trai. Định nghĩa trên chưa phân biệt dậy thì sớm trung ương hay dậy thì sớm ngoại vi, dậy thì sớm không hoàn toàn.

Trong khi đó, các dấu hiệu lâm sàng không đặc hiệu để phân biệt các thể dậy thì sớm của trẻ gái. Hơn nữa, nếu không được chẩn đoán và điều trị sớm trẻ sẽ có các rối loạn tâm sinh lý do sự hoạt động sớm trước tuổi trục hạ đồi - tuyến yên - tuyến sinh dục và hạn chế phát triển chiều cao cuối. Chính vì vậy đề tài này nghiên cứu một số đặc điểm lâm sàng và xét nghiệm nhằm có định hướng chẩn đoán sớm các thể dậy thì trong điều kiện $\mathrm{y}$ tế nước ta.

\section{2. ĐỐI TƯợNG VÀ PHƯƠNG PHÁP NGHIÊN CÚU}

Các bệnh nhi nữ được chẩn đoán dậy thì sớm tại khoa Nhi, Bệnh viện Đại học Y Dược Huế và Trung tâm Nhi, Bệnh viện Trung ương Huế, từ tháng 3 năm 2010 đến tháng 3 năm 2016.

\subsection{Tiêu chuẩn chọn bệnh}

Bệnh nhi nữ có tuyến vú phát triển trước 8 tuổi \pm có chu kỳ kinh nguyệt đầu tiên trước 10 tuổi theo tiêu chuẩn chẩn đoán dậy thì sớm [10],[12]. Nghiên cứu có 83 bệnh nhi đủ tiêu chuẩn chọn bệnh và được thăm khám, xét nghiệm cận lâm sàng.

\subsection{Tiêu chuẩn loại trừ}

Bệnh nhi nữ dậy thì sớm có nguyên nhân : Các bệnh lý ở hệ thần kinh trung ương như u não, các dị tật hoặc chấn thương, các bệnh lý nội tiết như tăng sản thượng thận bẩm sinh, suy giáp bẩm sinh. Bệnh lý tại tuyến thượng thận: u vỏ thượng thận...

Bệnh nhi không đồng ý tham gia nghiên cứu.

\section{Các biến số nghiên cứu:}

Tiền sử gia đình

Có chị và/hoặc me có kinh nguyệt sớm: Chu kỳ kinh đầu tiên trước 11 tuổi gọi là kinh nguyệt sớm.

\section{Khám lâm sàng:}

Chiều cao đứng đo bằng $\mathrm{cm}$; Cân nặng tính bằng $\mathrm{kg}$; Chỉ số BMI được đánh giá theo tiêu chuẩn của WHO 2007.

Đánh giá phát triển dậy thì tuyến vú $(\mathrm{B})$ và lông mu (P) theo phân loại Tanner.

Siêu âm tử cung buồng trúng:

Đo chiều cao tử cung tính bằng $\mathrm{mm}$. Đánh giá chiều cao tử cung theo tuổi: tăng/ bình thường [8].

Xác định có hay không các nang noãn > $5 \mathrm{~mm}$ chứng tỏ buồng trứng đã trưởng thành [8], [20].

Định lự̣ng các nồng độ hormon sinh duc nüFSH-LH-Estradiol

Nồng độ các hormon nền lấy máu khi đói sau khi đã làm các bước trên.

Nồng độ các hormon sau làm test động aGnRH liều thấp (Dipherelin ${ }^{\circledR} 0,1 \mathrm{mg}$ ):

Xét nghiệm các hormon bằng kỹ thuật điện hóa phát quang trên máy ELECYS 1010.

\section{Phân loại dậy thì sớm}

+ Dậy thì sớm trung ương:

Lâm sàng bệnh nhi có dấu hiệu dậy thì sớm và nồng độ hormone $\mathrm{LH} \geq 5 \mathrm{mUI} / \mathrm{ml}$ sau test Dipherelin ${ }^{\circledR} 0,1 \mathrm{mg}$ tiêm dưới da 60 phút [16]. Có 15 trường hợp bệnh nhi được chẩn đoán dật thì sớm trung ương không cần làm test động mà dựa vào các dấu hiệu lâm sàng rõ rệt là: có dấu hiệu dậy thì sớm với phát triển tuyển vú và lông $\mathrm{mu} \pm$ có kinh nguyệt. [1].

+ Dậy thì sớm ngoại vi: lâm sàng bệnh nhi có triệu chứng dậy thì sớm và nồng độ hormone $\mathrm{LH}<5 \mathrm{mUI} / \mathrm{ml}$ sau test Dipherelin ${ }^{\circledR}$ $0,1 \mathrm{mg}$ tiêm dưới da 60 phút [17].

2.3. Phương pháp nghiên cứu: Mô tả cắt ngang.

2.4. Xử lý số liệu: Phần mềm Medcalc 12.7 và Microsoft Excel 2010. 


\section{KẾT QUẢ NGHIÊN CÚU}

\section{1. Đặc điểm chung của nhóm nghiên cứu}

Bảng 1. Địa dư

\begin{tabular}{|c|c|c|c|}
\hline Địa dư $(\mathbf{n}=\mathbf{8 3})$ & DTS trung ương & DTS ngoại vi & \multirow{2}{*}{$\boldsymbol{\chi}^{\mathbf{2}} \mathbf{p}$} \\
\hline Thành phố & 20 & 21 & \multirow{2}{*}{3,906} \\
\hline Nông thôn & 11 & 32 & $>0,05$ \\
\hline Tổng & $\mathbf{3 1}$ & $\mathbf{5 2}$ & \\
\hline
\end{tabular}

Bảng 2. Tuổi tại thời điểm chẩn đoán dậy thì sớm

\begin{tabular}{|c|c|c|c|}
\hline $\begin{array}{c}\text { Thời điểm } \\
\text { chẩn đoán }\end{array}$ & $\begin{array}{c}\text { DTS trung ương } \\
\mathbf{N}=\mathbf{3 1}\end{array}$ & $\begin{array}{c}\text { DTS ngoại vi } \\
\mathbf{N = \mathbf { 5 2 }}\end{array}$ & $\mathrm{p}$ \\
\hline $\begin{array}{c}\text { Tuồi (năm) } \\
5,11 \pm 2,63\end{array}$ & $7,09 \pm 1,98$ & $3,93 \pm 2,22$ & $<0,0001$ \\
\hline
\end{tabular}

Bảng 3. Tiền sử gia đình với phân loại dậy thì sớm

\begin{tabular}{|c|c|c|c|c|}
\hline $\begin{array}{c}\text { Mẹ và/hoặc chị có kinh } \\
\text { nguyệt sớm }(\mathbf{n}=\mathbf{8 3})\end{array}$ & DTS trung ương & DTS ngoại vi & \multirow{2}{*}{$\boldsymbol{\chi}^{\mathbf{2}}$} & $\mathbf{p}$ \\
\hline Có & 18 & 11 & & \multirow{2}{*}{10,07} \\
\cline { 1 - 3 } Không & 13 & 41 & & \\
\hline Tổng & $\mathbf{3 1}$ & $\mathbf{5 2}$ & \\
\hline
\end{tabular}

\section{2. Đặc điểm lâm sàng}

Bảng 4. Đặc điểm phát triển chiều cao theo tuổi với phân loại dậy thì sớm

\begin{tabular}{|l|c|c|c|c|}
\hline $\begin{array}{c}\text { Chiều cao } \\
\text { theo tuổi }\end{array}$ & $\begin{array}{c}\text { DTS trung ương } \\
\mathbf{N = 3 1}\end{array}$ & $\begin{array}{c}\text { DTS ngoại vi } \\
\mathbf{N = 5 2}\end{array}$ & \multirow{2}{*}{$\boldsymbol{\chi}^{\mathbf{2}}$} & \multirow{2}{*}{$\mathbf{p}$} \\
\hline Tăng -CC > +2SD & 22 & 16 & \multirow{2}{*}{9,12} & \multirow{2}{*}{$<0,05$} \\
\cline { 1 - 3 } Bình thường & 11 & 36 & & \\
\hline Thấp-CC <-2SD & 0 & 0 & \\
\hline
\end{tabular}

Bảng 5. Đặc điểm BMI theo tuổi với phân loại dậy thì sớm

\begin{tabular}{|l|c|c|c|c|}
\hline \multicolumn{1}{|c|}{ BMI theo tuổi } & $\begin{array}{c}\text { DTS trung ương } \\
\mathbf{N = 3 1}\end{array}$ & $\begin{array}{c}\text { DTS ngoại vi } \\
\mathbf{N = 5 2}\end{array}$ & $\boldsymbol{\chi}^{\mathbf{2}}$ & p \\
\hline Tăng cân, béo phì & 9 & 35 & & \\
\cline { 1 - 3 } & 22 & 17 & \multirow{2}{*}{9,94} & \\
\hline Gầy $(\mathrm{n}=0)$ & 0 & 0 & 0,01 \\
\hline
\end{tabular}

Bảng 6. Các giai đoạn dậy thì theo phân loại dậy thì sớm

\begin{tabular}{|l|c|c|c|}
\hline & $\begin{array}{c}\text { DTS trung ưong } \\
\mathbf{N = 3 1}\end{array}$ & $\begin{array}{c}\text { DTS ngoại vi } \\
\mathbf{N = 5 2}\end{array}$ & p \\
\hline B2 & 8 & 39 & \\
B3 & 12 & 13 & $<0,001$ \\
\hline B4 & 10 & & $<$ \\
\hline
\end{tabular}




\begin{tabular}{|l|c|c|}
\hline B5 & 1 & \\
\hline P1 & 22 & 52 \\
\hline P2 & 6 & 0 \\
\hline P3 & 3 & 0 \\
\hline Có kinh nguyệt & 9 & 29,03 \\
\hline
\end{tabular}

\section{3. Đặc điểm tuổi xương}

Bảng 7. Đặc điểm tuổi xương

\begin{tabular}{|c|c|c|c|}
\hline & $\begin{array}{l}\text { DTS trung ương } \\
\qquad \mathbf{N}=31\end{array}$ & $\begin{array}{c}\text { DTS ngoại vi } \\
\quad \mathrm{N}=5 \mathbf{5}\end{array}$ & $\chi^{2} \mathbf{p}$ \\
\hline Tuổi xương lớn hơn tuổi thực & 16 & 3 & 20,15 \\
\hline Tuổi xương tương đương tuổi thực & 15 & 48 & $<0,0001$ \\
\hline
\end{tabular}

3.4. Đặc điểm siêu âm tử cung - buồng trứng

Bảng 8. Chiều cao tử cungtheo phân loại dậy thì sớm

\begin{tabular}{|c|l|c|c|c|c|}
\hline \multicolumn{2}{|c|}{ Chiều cao tử cung (mm) } & DTS trung ương & DTS ngoại vi & $\chi^{\mathbf{2}}$ & \multicolumn{1}{|c|}{ p } \\
\hline \multicolumn{2}{|c|}{$\overline{\boldsymbol{X}} \pm$ SD } & $44,47 \pm 9,79$ & $30,21 \pm 8,20$ & \multicolumn{2}{|c|}{$<\mathbf{0 , 0 5}$} \\
\hline \multirow{2}{*}{$\begin{array}{c}\text { Chiều cao tử } \\
\text { cung theo tuổi }\end{array}$} & Tăng & 24 & 8 & & $<0,0001$ \\
\cline { 2 - 4 } & $\begin{array}{l}\text { Bình } \\
\text { thường }\end{array}$ & 7 & 44 & & \\
\hline
\end{tabular}

Bảng 9. Nang noãn với phân loại dậy thì sớm

\begin{tabular}{|l|c|c|c|c|}
\hline \multicolumn{1}{|c|}{ Nang noãn > 5mm } & DTS trung ương & DTS ngoại biên & \multirow{2}{*}{$\boldsymbol{\chi}^{\mathbf{2}}$} & p \\
\hline Có & 13 & 7 & & \\
\cline { 1 - 3 } Không & 18 & 45 & \multirow{2}{*}{7,12} & $<0,005$ \\
\hline Tổng & $\mathbf{3 1}$ & $\mathbf{5 2}$ & & \\
\hline
\end{tabular}

3.5. Nồng độ các hormon nền trục sinh dục FSH-LH-E2 theo phân loại dậy thì sớm

Bảng 10. Nồng độ các hormon nền trục sinh dục FSH - LHvà Estradiol trong test aGnRH

\begin{tabular}{|c|c|c|c|}
\hline $\begin{array}{l}\text { Nồng độ hormon } \\
\text { Trung vị }(95 \% \text { CI) }\end{array}$ & $\begin{array}{l}\text { DTS trung ưong } \\
\mathrm{N}=\mathbf{1 6}\end{array}$ & $\begin{array}{l}\text { TDS ngoại vi } \\
\quad \mathrm{N}=52\end{array}$ & $\mathbf{p}$ \\
\hline LHnền $(\mathrm{mUI} / \mathrm{ml})$ & $0,64(0,19-3,10)$ & $0,10(0,10-0,10)$ & $<0,0001$ \\
\hline LH đỉnh & $9,34(5,49-23,30)$ & $2,36(1,41-3,08)$ & $<0,0001$ \\
\hline FSH nền $(\mathrm{mIU} / \mathrm{ml})$ & $3,40(2,56-5,47)$ & $2,00(1,65-2,89)$ & $<0,01$ \\
\hline FSH đỉnh & $12,27(8,63-15,20)$ & $9,38(7,77-14,83)$ & $>0,05$ \\
\hline LH/FSH & 1,28 & 0,29 & \\
\hline Estradiolnền $(\mathrm{pg} / \mathrm{ml})$ & $23,0(7,7-34,8)$ & $10,00(5,0-10,00)$ & $>0,05$ \\
\hline
\end{tabular}

\section{BÀN LUẬN}

\section{1. Đặc điểm chung của nhóm nghiên} cứu

\section{Đặc điểm địa du}

Theo bảng 3.1 cho thấy trẻ gái dậy thì sớm sống ở thành phố chiếm lớn hơn với số trẻở nông thôn $(\mathrm{p}<0,05)$. Tương tự nghiên cứu của Nguyễn Thị Hồng Đào về đặc điểm lâm sàng và các yếu tố liên quan đến trẻ gái dậy thì sớm hoàn toàn tại bệnh viện đa khoa tỉnh Bình Định năm 2013 thì tỷ lệ này là $78,6 \%$ và $21,4 \%$ [1]. Nguyễn Thị Kiều Oanh và Võ 
Minh Tuấn (2008) cho thấy nhóm trẻ sống ở trung tâm dậy thì sớm hoàn toàn hơn 1,33 lần so với trẻ sống vùng ven [4].

Có sự khác biệt tỷ lệ trẻ gái dậy thì sớm giữa thành phố và nông thôn có lẽ do kinh tế văn hoá, dinh dưỡng ảnh hưởng đến dậy thì của trẻ.

\section{Tuổi đến khám}

Theo bảng 3.2 tuổi đến khám lần đầu của trẻ gái dậy thì sớm trung bình $5,11 \pm 2,63$. Tương tự các nghiên cứu trong nước và ngoài nước: Nghiêncứu tại bệnh viện Nhi Đồng 1 từ 2008 đến 2013 của Nguyễn Phương Khanh, Huỳnh Thoại Loan (2013) thì tuổi dậy thì sớm trung bình là 5,5 $\pm 2,5$ tuổi [2]. Tại Trung Quốc, Wen-Jing Li và cộng sự (2015) nghiên cứu ở 236 bé gái được chẩn đoán dậy thì sớm vô căn từ 4/2012 - 2/2014 có tuổi trung bình là $6,4 \pm 1,0$ tuổi [19]. Ở Hàn Quốc, nghiên cứu của Kim DooSoo và cộng sự (2012) cho thấy tuổi trung bình của trẻ dậy thì sớm trung ương $7,3 \pm 0,6$, dậy thì sớm ngoại vi $6,5 \pm 0,3$ tuồi [15]. Điều này chứng tỏ dậy thì sớm ở trẻ gái tại các vùng ở nước ta khá tương đồng với các nước châu Á.

Bảng 3.2 cũng cho thấy có sự khác biệt rõ rệt tuổi ở thời điểm chẩn đoán, nhóm dậy thì sớm ngoại biên là tuyến vú phát triển sớm có tuổi trung bình là $3,93 \pm 2,22$ nhỏ hơn một cách có ý nghĩa tuổi của nhóm dậy thì sớm trung ương. Kết quả này phù hợp với các nghiên cứu khác. Khi tuyến vú xuất hiện trước 3 tuổi chủ yếu là tình trạng tuyến vú phát triển sớm đơn độc.

Ở lứa tuổi 5- 8 tuổi tuyến vú phát triển thường là dấu hiệu đầu tiên của dậy thì sớm thật.

Do đó, đặc điểm tuổi xuất hiện tuyến vú là dữ kiện quan trọng có giá trị định hướng chẩn đoán [10],[12].

Tiền sử mẹ và/hoặc chị gái có kinh nguyệt sớm

Theo nghiên cứu của chúng tôi nhóm dậy thì sớm trung ương có mẹ và/hoặc chị có kinh nguyệt sớm cao hơn nhóm dậy thì ngoại biên, $\mathrm{p}<0,05$ (bảng 3 ).

Nghiên cứu này cũng có kết quả tương tự nghiên cứu trong nước[1], [4]. Kılıç và cộng sự (2012) nghiên cứu đặc điểm lâm sàng và cận lâm sàng ở trẻ em dậy thì sớm có $13,8 \%$ trong 128 trẻ gái dậy thì sớm có mẹ có kinh nguyệt sớm [16]. Vai trò di truyền trong dậy thì sớm đã được xác nhận trong các nghiên cứu gần đây. Kisspeptin-GPR54 có vai trò quan trọng, trực tiếp kích hoạt tế bào thần kinh tiết GnRH, kích thích trục dưới đồi tuyến yên - tuyến sinh dục kích hoạt dậy thì. Kisspeptin là một protein được mã hóa bởi gen KiSS-1. Gen này nằm trên cánh tay dài của nhiễm sắc thể số 1 (1q32).

\section{2.Đặc điểm lâm sàng}

Tăng phát triển chiều cao: Bảng 4 nhận xét về phát triển chiều cao cũng khác biệt rõ giữa 2 nhóm, do nhóm DTS ngoại biên độ tuổi chẩn đoán nhỏ hơn nhiều. Hơn nữa, dậy thì sớm trung ương có thể được biểu hiện bởi tăng phát triển chiều cao nhiều tháng trước khi phát triển tuyến vú. Kết quả này phù hợp với các nghiên cứu khác và y văn là chiều cao của trẻ giai đoạn dậy thì tăng rất nhanh, trẻ gái có thể tăng trung bình $7,5 \mathrm{~cm} /$ năm. Tuy nhiên ở trẻ dậy thì sớm thì đỉnh tăng trưởng xuất hiện sớm nhưng cũng kết thúc sớm làm chiều cao chính thức của trẻ giảm[3]. Theo Carel (2008) thì trẻ gái dậy thì sớm có chiều cao cuối thấp hơn khoảng $12 \mathrm{~cm}$ so với trẻ khỏe mạnh cùng tuổi [10].

Thừa cân - béo phì - BMI tăng: Bảng 5 cho thấy BMI là yếu tố liên quan đến phân loại dậy thì sớm với $\mathrm{p}<0,01$. Theo nhận định của một số tác giả thì cơ thể trẻ gái chỉ bắt đầu dậy thì khi có chỉ số khối cơ thể tới hạn. Khi cơ thể phát triển về chiều cao và cân nặng đến một mức tới hạn sẽ như là một tín hiệu khởi động quá trình dậy thì, liên quan đến leptin là một hormone polypeptid được tổng hợp trong các tế bào mỡ, điều hòa sự ăn uống và tiêu thụ năng lượng ở trung tâm dưới đồi. Leptin có thể là một trong những yếu tố đầu tiên của báo hiệu sự trưởng thành của trung tâm dưới đồi gây tiết có xung GnRH làm tăng tiết horrmone LH, FSH [3]. Một nghiên cứu theo dõi dọc của Freedman (2003) tìm thấy rằng những bé gái béo phì thì có xu hướng có kinh nguyệt sớm hơn những bé gái gầy[12]. Theo Võ Minh Tuấn, Nguyễn Thị Trần Minh 
(2009) nghiên cứu có liên quan giữa BMI và tuổi kinh đầu, tuổi kinh đầu càng sớm BMI tại thời điểm nghiên cứu càng cao [5].

Các giai đoạn dậy thì: Đa số nhóm trẻ tuyến vú phát triển sớm có giai đoạn phát triển tuyến vú ở giai đoạn B2, B3 (Bảng 6), trong khi nhóm dậy thì sớm trung ương tuyến vú phát triển ở các giai đoạn từ $\mathrm{B} 2$ đến $\mathrm{B} 5$ và có lông mu phát triển $\mathrm{P} 2, \mathrm{P} 3$, có đến 9 cas chỉ đến khám khi đã có kinh nguyệt. Kết quả này phù hợp với tiến triển trên lâm sàng của 2 thể dậy thì sớm của trẻ gái. Trong dậy thì sớm ngoại biên chỉ có một đặc tính sinh dục phụ xuất hiện,thường gặp nhất bao gồm tuyến vú phát triển sớm đơn độc (premature thelarche), kéo dài đến tuổi dậy thì bình thường. Nguyên nhân hay gặp nhất của thể dậy thì sớm này là do các nguyên nhân gây tăng tiết hormon sinh dục nữ nhưng chưa có hoạt động của trục sinh dục [10], [13].

Phát triển tuyến vú sớm trước 8 tuổi ở trẻ gái có thể liên quan đến 3 tình huống lâm sàng sau: Có thể là dấu hiệu đầu tiên của dậy thì sớmtrung ương,có thể là trường hợp tuyến vú phát triển sớm đơn độc, hay hiếm hơn nữa, là dấu hiệu thứ phát do tiết u tiết estrogen của buồng trứng hay tuyến thượng thận [10],[13]. Trong dậy thì sớm trung ương, dậy thì là kết quả của một sự hoạt động hay lại hoạt động của trục hạ đồi - tuyến yên - tuyến sinh dục do đó trẻ có các giai đoạn phát triển tính dục khác nhau.

Tuổi xương: Bảng 7 cho thấy tuổi xương liên quan đến phân loại dậy thì sớm có ý nghĩa thống kê $(p<0,0001)$. Khi trẻ dậy thì sớm, nồng độ hormon sinh dục tăng gây ảnh hưởng đến sự cốt hóa xương làm cho tuổi xương lớn hơn tuổi thực. Kết quả này phù hợp với kết quả chiều cao cũng liên quan đến phân loại dậy thì sớm trung ương. Giai đoạn 4 của dậy thì (trước chu kỳ kinh đầu tiên), mức tăng của estrogen đã làm cốt hóa hầu hết các đầu xương, các bé gái đã gần đạt được chiều cao cuối[1],[3]. Nghiên cứu của K1lıç Ayşe và cộng sự (2012) cho thấy tuổi xương ở nhóm dậy thì sớm thật lớn hơn nhóm tuyến vú và lông mu phát triển sớm, và sự khác biệt này có ý nghĩa thống kê [16].

\subsection{Các xét nghiệm cận lâm sàng}

Siêu âm tử cung - buồng trứng

Bảng 8 và 9 cho thấy có sự khác biệt rõ rệt các chỉ số siêu âm tử cung-buồng trứng theo phân loại dậy thì sớm trung ương và ngoại biên. Kết quả này phù hợp với các nghiên cứu khác. Một số tác giả nghiên cứu về siêu âm tử cung - buồng trứng ở trẻ dậy thì sớm cho rằng có thể sử dụng chỉ số chiều cao tử cung để phân biệt giữa tuyến vú phát triển sớm và dậy thì sớm trung ương [8],[20],[22]. Coll và cộng sự từ năm 1984 đã xác định chiều cao tử cung là yếu tố có giá trị để đánh giá mức độ ngấm estrogen [20].

Toublanc xác định ngưỡng bắt đầu dậy thì của chiều cao tử cung là $35 \mathrm{~mm}$ [22]. Theo các tác giả hình ảnh buồng trứng có nhiều nang noãn $>5 \mathrm{~mm}$ xuất hiện ở các trẻ gái chưa dậy thì ở khoảng 7 tuổi, được coi là chỉ điểm cho sự tiết theo nhịp của hormon hướng sinh dục được điều hòa bởi cơ chế feedback dương tính của thời điểm bắt đầu dậy thì [8], [20],[22].

Tuy nhiên, siêu âm tử cung buồng trứng là một xét nghiệm kỹ thuật có giá trị chẩn đoán cao nhưng đòi hỏi có kỹ thuật viên được huấn luyện tốt, và phải hẹn chuẩn bị tốt cho bệnh nhân, nhất là các trẻ gái nhỏ khó thực hiện kỹ thuật này. Chính trong nghiên cứu này chúng tôi không thể đo kích thước buồng trứng ở một số trẻ nhỏ.

\section{Định lượng nồng độ hormon trục sinh dục nền}

Bảng 10. cho thấy có khác biệt rõ rệt nồng độ hormon trục sinh dục FSH, LH nền theo phân loại dậy thì. Kết quả này phù hợp với kết quả của một số nghiên cứu cũng định lượng $\mathrm{FSH}$ bằng phương pháp định lượng siêu nhạy dùng 2 kháng thể đơn dòng [7], [9],[14],[18].

Ilicki và cs [13] lại tìm thấy nồng độ FSH cao ở nhóm vú phát triển sớm hơn là ở nhóm trẻ chưa dậy thì cũng độ tuổi. Các kết quả nghiên cứu do vậy còn chưa thống nhất, và do đó sẽ rất khó khăn để chẩn đoán phân biệt giữa DTS và DTS không hoàn toàn bằng cách dựa vào nồng độ $\mathrm{FSH}$.

Nồng độ $L H$ nền tăng cao có ý nghĩa, 
$\mathrm{p}<0,0001$ trong dậy thì trung ương. Apter với phương pháp IFMA cho thấy nồng độ $\mathrm{LH}$ tăng cao một cách rõ rệt từ khi bắt đầu dậy thì, nồng độ LH tăng trung bình giữa trẻ gái 7 tuổi và người nữ trưởng thành là 116 lần. FSH tăng cao chỉ là 6,7 lần, estradiol là 12 lần [7], cácnghiên cứu mới đây cũng nhận xét tương tự. Hormone LH, FSH nền dùng để chẩn đoán dậy thì sớm trung ương có độ nhạy thấp và nhịp tiết horrmone LH có xung nên nhiều tác giả vẫn đề nghị test $\mathrm{LH}-\mathrm{RH}$ là tiêu chuẩn vàng để chẩn đoán dậy thì sớm trung ương[14]. Nồng độ estradiol không liên quan đến phân loại dậy thì sớm, $\mathrm{p}>0,05$. Estradiol chủ yếu do các tế bào hạt của lớp áo trong của nang trứng bài tiết trong nửa đầu chu kỳ kinh nguyệt và nửa sau do hoàng thể bài tiết chủ yếu ở buồng trứng. Theo Carel JC (2008) thì ở trẻ gái, nồng độ estradiol rất thay đổi và có độ nhạy thấp để chẩn đoán dậy thì sớm trung ương [11].

\section{Nồng độ LH-FSH đỉnh:}

Xét nghiệm cơ bản nhất có giá trị chẩn đoán dậy thì sớm trung ương được xem là tiêu chuẩn vàng là nghiệm pháp LH-RH. Tuy nhiên do nghiệm pháp LH-RHcó giá thành cao, không thể thực hiện một cách rộng rãi, nên nhiều nghiên cứu đã thay bằng $\mathrm{aGnRH}$ (Triptorelin - Dipherelin (® 0,1 mg) có giá thành thấp hơn và dễ thực hiện. Nhiều nghiên cứu đã xác định Dipherelin ${ }^{\circledR} 0,1 \mathrm{mg}$ có thể chẩn đoán dậy thì sớm trung ương với độ chính xác cao và được sử dụng thay chotest LH - RH cổ điển[6], [17].

Nồng độ hormon LH đỉnh và tỷ sốLH/FSH sau test động Dipherelin ${ }^{\circledR} 0,1 \mathrm{mg}$, có khác biệt rõ rệt giữa 2 nhóm dậy thì sớm trung ương với dậy thì sớm ngoại vi. Trong khi nồng độ hormon FSH không có sự khác biệt có ý nghĩa. Kết quả này phù hợp với các nghiên cứu khác không tìm thấy các giá trị chẩn đoán của nồng độ FSH trong dậy thì ở giới nữ [13],[14],[15],[16].

\section{KẾT LUẬN}

Về lâm sàng, đặc điểm tuổi xuất hiện tuyến vú là dữ kiện quan trọng có giá trị định hướng chẩn đoán sớm các thể dậy thì; tuổi xương lớn hơn tuổi thực một cách có ý nghĩa ( $>1$ năm) cũng là biểu hiện của dậy thì sớm trung ương.

Về cận lâm sàng, siêu âm tư cung buồng trúng là một xét nghiệm kỹ thuật có giá trị chẩn đoán cao nhưng đòi hỏi có kỹ thuật viên được huấn luyện tốt, và phải hẹn chuẩn bị tốt cho bệnh nhân. Phương pháp định lượng nồng độ hormon $\mathrm{LH}$ nền bằng các phương pháp miễn dịch thế hệ 2 có thể đánh giá mức độ trưởng thành của trục hướng sinh dục. Có thể sử dụng test động $\mathrm{aGnRH}$ liều thấp để phân biệt dậy thì sớm trung ương và dậy thì sớm ngoại vi.

\section{TÀI LIỆU THAM KHẢO}

1. Nguyễn Thị Hồng Đào (2013), Nghiên cứu đặc điểm lâm sàng và các yếu tố liên quan đến trẻ gái dậy thì sớm hoàn toàn tại bệnh viện đa khoa tỉnh Bình Định, Luận án chuyên khoa cấp II, Đại học Y Dược Huế.

2. Nguyễn Phương Khanh, Huỳnh Thoại Loan (2014) "Đặc điểm các trường hợp dậy thì sớm trung ương tại bệnh viện Nhi Đồng 1 từ 2008 đến nay", Hội nghị nhi khoa 2014.

3. Kerdanete De M, Hoàng Thị Thủy Yên (3/2005) "Giá trị của niệu bào đồ trong chẩn đoán dậy thì sớm thật vô căn của trẻ gái”, Tạp chí nghiên cúu y học, 35 (2), tr. 30-35.

4. Nguyễn Thị Kiều Oanh*, Võ Minh Tuấn (2008), "Tuổi dậy thì và các yếu tố liên quan ó học sinh nũ $8-11$ tuổi tại TP HCM", Tạp chí Y học TP. Hồ Chí Minh 2009, 13 (1), tr. 92 - 98.

5. Võ Minh Tuấn, Nguyễn Thị Trần Minh (2009), "Tuổi có kinh lần đầu và các yếu tố liên quan ở học sinh nữ phổ thông cơ sở tỉnh Bình Phước", Tạp chí Y hoc TP. Hồ Chí Minh, 14(1), tr. 283 - 288.

6. Analía Verónica Freire, María Eugenia Escobar, Mirta Graciela Gryngarten, Andrea Josefina Arcari, María Gabriela Ballerini, Ignacio Bergadá, María Gabriela Ropelato (2013), "High Diagnostic Accuracy of Subcutaneous Triptorelin Test Compared With GnRH 
Test for Diagnosing Central Precocious Puberty in Girls", Clin Endocrinol. 2013;78(3):398-404.

7. Apter D., Cacciatore B., Alfthan H., Steman U.H. (1989), "Serum Luteinizing Hormone concentrations increase 100 fold in females from 7 years of age to adulthood, as measured by time - resolved Immunofluorometric Assay",J Clin Endocrinol Metab,68, pp.53 -57.

8. Battaglia C., Mancini F., Regnani G., Persico N., Iughetti L., De Aloysio D. (2003), "Pelvic ultrasound and color Doppler findings in different isosexual precocities", Ultrasound Obstet Gynecol, 22 (3) pp.277-83.

9. Brito N V, Batista C M, Borges F M et al (1999), "Diagnostic value of fluorometric assays in the evaluation of precocious puberty", The journal of Clinical endocrinology \& metabolism, 84(10), pp. 3539 - 3544.

10. Carel, J.C. \& Léger, J. (2008) Precocious puberty. The New EnglandJournal of Medicine, 358, 2366 - 2377.

11. Carel, J.C., Eugster, E.A., Rogol, A. et al. (2009) Consensus statement on the use of gonadotropin-releasing hormone analogs in children. Pediatrics, 123, e752 - e762.

12. Freedman D S, et al (2003), "The relation of menarche age to obesity in childhood and adulthood: The Bogalusa heart study", BMC pediatric, 3, pp. 1 - 9.

13. IlickiA, Prager Lewin R, Kauli R et coll. (1984),"Premature thelarche- Natural history and sex hormone secretion in 68 girls". Acta Paediatre Scand,73:756-762.

14. Lee D S, Ryoo N Y, Lee S H, et al (2013), "Basal luteinizing hormone and follicular stimulating hormone: is it suficent for the diagnosis of prcocious?",
Ann Pediatr Endocrinol Metab,18, pp. 196-201.

15. Kim D, Cho S Y, Maeng S, et al (2012), "Diagnosis and constitutional and laboratory features of Korean girls referred for precocious puberty", Korean J Pediatric,55(12), pp. 481- 486.

16. K1lıç A, Durmuş S M, Ünüvar E, et al (2012), "Clinical and Laboratory Characteristics of Children Referred for Early Puberty: Preponderance in 7-8 Years of Age", Pediatr En docrinol, 4(4), pp. 208-212.

17. Poomthavorn $\mathrm{P}$, Khlairit $\mathrm{P}$, Mahachoklertwattana P (2009), "Subcutaneous Gonadotropin Releasing hormone agonist (Triptorelin) test for diagnosing precocious puberty", Hormoneresearch, 72, pp. $114-119$.

18. Resende, E.A.M.R., Lara, B.H.J., Reis, J.D. et al. (2007) Assessment of basal and gonadotropin-releasing hormonestimulated gonadotropins by immunochemiluminometric and immunofluorometric assays in normal children. The Journal of Clinical Endocrinology and Metabolism, 92, 1424-1429.

19. Li W J,Gong C X, Guo M J, et al (2015), "Efficacy and safety of domestic Leuprorelin in girls with idiopathic central precocious puberty", Chinese MedicalJournal, 128, pp. 1314 - 1320.

20. Colle M., Calabet A., Cadier L., Battin J. (1984), Données de l'échographie pelvienne au cours du développement normal et pathologique chez la fille". Arch Fr Pediatr, 41, pp.405-408.

21. Toublanc J.E. (1996), "Gynécologie pédiatrique de la petite fille", Journees parisiennes de Pediatrie, Medecine,Science. Ed Flamarion. 